\title{
miR-200c: a versatile watchdog in cancer progression, EMT, and drug resistance
}

\author{
Merve Mutlu $^{1}$ - Umar $\operatorname{Raza}^{1}$ • Özge Saatci ${ }^{1}$ - Erol Eyüpoğlu ${ }^{1} \cdot$ Emre Yurdusev $^{1}$ • \\ Özgür Șahin ${ }^{1}$
}

Received: 21 February 2016 /Revised: 5 April 2016/Accepted: 11 April 2016/Published online: 20 April 2016

(C) Springer-Verlag Berlin Heidelberg 2016

\begin{abstract}
MicroRNAs (miRNAs) are 20-22-nucleotide small endogenous non-coding RNAs which regulate gene expression at post-transcriptional level. In the last two decades, identification of almost 2600 miRNAs in human and their potential to be modulated opened a new avenue to target almost all hallmarks of cancer. miRNAs have been classified as tumor suppressors or oncogenes depending on the phenotype they induce, the targets they modulate, and the tissue where they function. miR-200c, an illustrious tumor suppressor, is one of the highly studied miRNAs in terms of development, stemness, proliferation, epithelial-mesenchymal transition (EMT), therapy resistance, and metastasis. In this review, we first focus on the regulation of miR-200c expression and its role in regulating EMT in a ZEB1/E-cadherin axis-dependent and ZEB1/E-cadherin axis-independent manner. We then describe the role of miR-200c in therapy resistance in terms of multidrug resistance, chemoresistance, targeted therapy resistance, and radiotherapy resistance in various cancer types. We highlight the importance of miR-200c at the intersection of EMT and chemoresistance. Furthermore, we show how miR-200c coordinates several important signaling cascades such as TGF- $\beta$ signaling, PI3K/Akt signaling, Notch signaling, VEGF signaling, and NF-KB signaling. Finally, we discuss miR-200c as a potential prognostic/diagnostic biomarker in several diseases, but mainly focusing on cancer and its potential application in future therapeutics.
\end{abstract}

Özgür Șahin

sahinozgur@gmail.com

1 Department of Molecular Biology and Genetics, Faculty of Science, Bilkent University, B Building SB-247, 06800 Ankara, Turkey
Keywords miR-200c $\cdot$ Epithelial-mesenchymal transition $($ EMT) $\cdot$ Drug resistance $\cdot$ TGF- $\beta$ - ZEB1/2 $\cdot$ Cell signaling $~$. Biomarker

\section{Introduction}

MicroRNAs (miRNAs), small non-coding RNAs that control gene expression at post-transcriptional level, were discovered only two decades ago, and their importance in cell biology is exponentially increasing since then $[1,2]$. Lin-4 gene, rather than being translated into a protein, transcribed into a pair of small RNAs (later termed as miRNAs) which imperfectly base-paired to complementary sequences in the 3'-UTR of different messenger RNAs (mRNAs), thus found to be involved in post-transcriptional gene regulation. Later, the discovery of the second miRNA, let-7 [3], and its sequence conservation across species from flies to human triggered seminal follow-up works to unveil the basic concepts of miRNA biogenesis and function [4-6]. Over the period of the last 15 years, a total of more than 24,000 miRNA loci have been discovered in 206 different species highlighting the potential key regulatory functions of miRNAs in several organisms [7]. To date, miRNAs have been estimated to regulate more than $60 \%$ of human genome [8] and dysregulated miRNA expression has been implicated in regulating various diseases and developmental disorders. Moreover, the packed structure of miRNAs led to their less vulnerability to degradation even in serum environment [9] ensuring their suitability for diagnostic and therapeutic purposes [10-12]. miR-200c was first shown to be dysregulated in several cancer cell lines [13]. Since then, miRNAs from miR-200 family, in general, but miR-200c, in particular, have been explored to have an impact on a large variety of biological processes and have been demonstrated to play crucial roles in epithelial-mesenchymal 
transition (EMT), cell invasion, proliferation, metastasis, apoptosis, autophagy, and therapy resistance in several cancer types $[14,15]$. There are more than 400 publications related to miR-200c depicting the importance of this miRNA; thus, the vast information about miR-200c deserves a compilation. In this review, we focus on the molecular functioning of miR$200 \mathrm{c}$ with special emphasis on regulation of EMT, cell invasion, therapy resistance, role in signaling pathways, and its potential as a biomarker in diverse diseases including cancer.

\section{Regulation of miR-200c expression}

miR-200 family is composed of two clusters: the miR-200a/b/ 429 cluster containing miR-200a, miR-200b, and miR-429 on chromosome $1 \mathrm{p} 36$ and the miR-200c/141 cluster containing miR-200c and miR-141 on chromosome 12p13 (Fig. 1). In addition to four enhancer boxes (E-box 1-4, CAGGTG), miR200c promoter has two specific sites (Z-box 1 and 2, CAGGTA) restricted for the binding of ZEB transcription factors [16]. ZEB1 alone or bound to different co-repressors such as CtBPs and BRG1 suppresses miR-200c expression $[17,18]$. On the other hand, P300/PCAF complex can activate miR-200c promoter via lysine acetylation of ZEB1 resulting in the release of ZEB1 suppression on miR-200c/141 transcription [19]. A study conducted on vMH neural progenitor cells revealed Sox2 and E2F3 as additional transcription factors regulating transcription from the miR-200c/141 gene cluster. Specific binding sites conserved across species (human, mouse, and rat) have been reported for Sox 2 and E2F at the distal (in the -1.4 to $-1.3 \mathrm{~kb}$ region with respect to the transcriptional start +1 of miR-200c/141 cluster) and proximal promoter regions ( -500 to $-400 \mathrm{bp}$ ), respectively [20]. c-Myb transcription factor also activates miR-200c gene through the binding sites located in -1653 to $-1647 \mathrm{bp}$ and -988 to $-982 \mathrm{bp}$ regions of the promoter [21]. Furthermore, the p53/ p63/p73 family of transcription factors has been reported to positively regulate miR-200c expression in ovarian cancer cells [22]. In mouse embryonic fibroblasts, stemness-related transcription factor, Oct4, in combination with Sox2, has been implicated to serve as an activator of miR-200c gene expression [23].

Epigenetic gene regulatory mechanisms, such as DNA methylation, are also capable of playing a predominant role in regulating the expression of miR-200c (Fig. 1). For instance, in breast cancer cells, miR-200c/141 cluster often undergoes aberrant silencing due to methylation of $\mathrm{CpG}$ island located in its promoter region [24]. In advanced stage bladder cancer and poorly differentiated breast cancer cell lines, miR200 expression, along with miR-205, is found to be silenced either due to promoter hypermethylation or due to direct binding of Twist transcriptional repressor on the promoter [25]. Interestingly, miR-200c, itself, can indirectly act as an epigenetic regulator. For example, ectopic expression of miR-200b or miR-200c in mesenchymal breast cancer cells resulted in partial upregulation of E-cadherin level due to the degradation of ZEB1-histone deacetylase repressor complexes and increase in the acetylation of histone $\mathrm{H} 3$ at the E-cadherin promoter [26]. Overall, in addition to transcriptional regulation of miR-200c, epigenetic mechanisms also play a critical role in tuning miR-200c expression and in regulating its downstream effects.

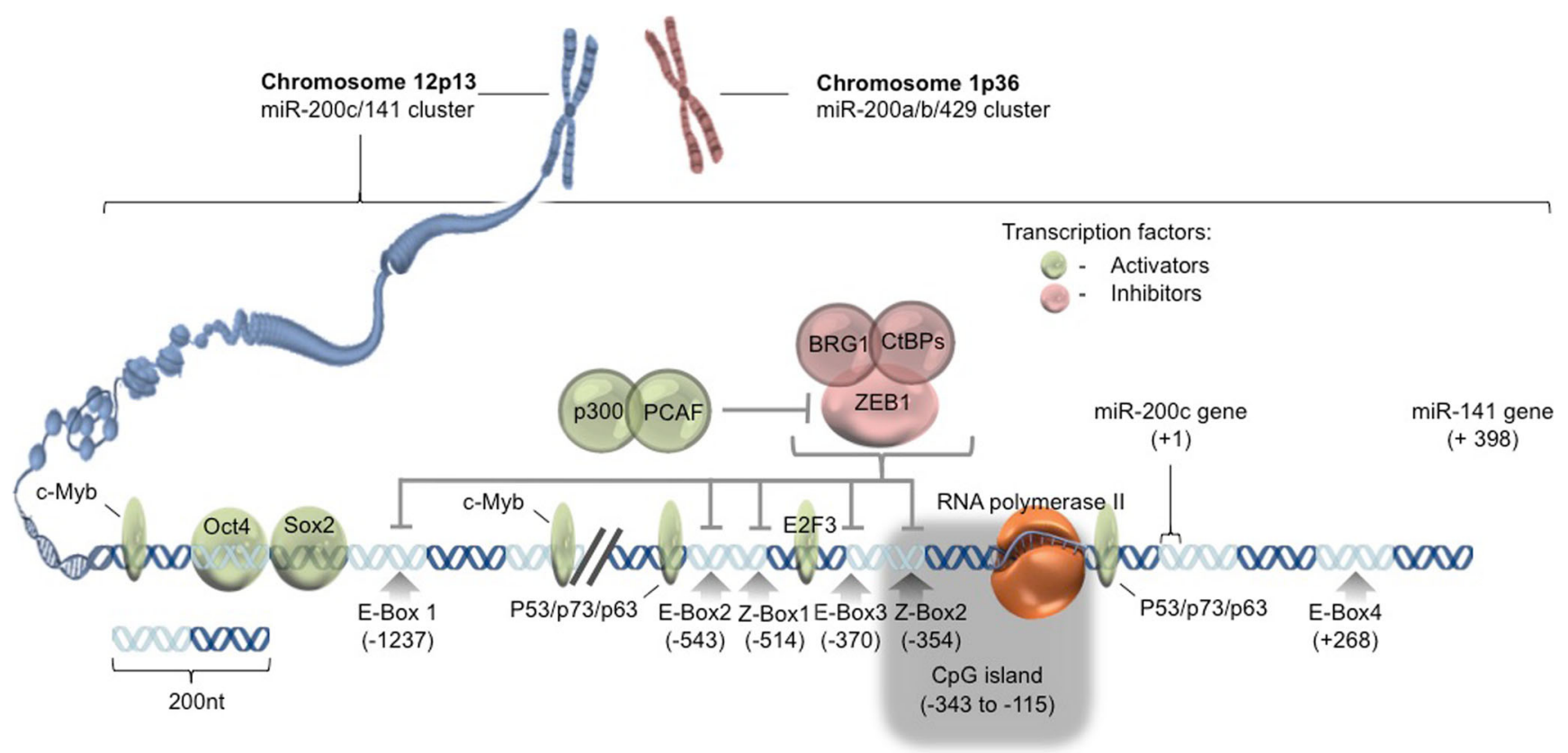

Fig. 1 Regulation of miR-200c expression. Graphical depiction of chromosomal position of miR-200c/141 gene cluster, promoter and enhancer sequences, and transcription factor binding sites 


\section{Role of miR-200c in epithelial-mesenchymal transition}

EMT, defined as transformation of immotile epithelial cells to motile and invasive mesenchymal cells by losing their cell-to-cell adhesion properties [27], is a crucial step in metastatic cascade. One of the hallmarks of EMT is functional loss of cell surface marker E-cadherin and gain of mesenchymal characteristics via elevating the levels of mesenchymal proteins such as vimentin, fibronectin 1 (FN1), and N-cadherin [28]. Transcription factors associated with EMT, notably ZEB1 and ZEB2, suppress Ecadherin expression and thus trigger the transformation of epithelial cells into mesenchymal state and subsequently initiate the early steps of metastasis [29, 30].

\section{miR-200c inhibits EMT via regulating ZEB1/2/E-cadherin axis}

miR-200 family members including miR-200c directly target and repress ZEB1 and ZEB2 expression [31] (Fig. 2), and their frequent loss with concomitant increase in ZEB1 and ZEB2 expression has been observed in different cancers promoting EMT by downregulating E- cadherin [16, 32, 33]. Conversely, ectopic expression of E-cadherin in mesenchymal cells promotes the reverse process and mesenchymal-epithelial transition, confirming bona fide effects $[31,34]$. For instance, via regulating miR-200c in a feedback loop, ZEB1 contributes to harbor stabilized EMT in invading cancer cells $[16,35]$. Interestingly, miR-200c-ZEB1 interaction-mediated EMT is also associated with acquisition of cancer stemness as miR-200c suppresses cancer stem cell (CSC)-like features by directly targeting ZEB1 as well as stem cell factors like Bmi1, Sox2, and K1f4 [33, 36]. ZEB1 expression has been shown to be high in embryonic stem (ES) cells, and the expression of miR-200 family members is positively correlated with ESC differentiation [33, 35, 37].

Furthermore, the other factors involved in regulation of miR-200c also hold significant importance in initiating metastatic cascade. For instance, tumor suppressor transcription factor, p53, has been demonstrated to suppress EMT and EMT-related cancer stemness via provoking transcriptional activation of $\mathrm{miR}-200 \mathrm{c}$ and associated downregulation of ZEB transcription factors [38, 39]. In addition, the $\mathrm{C}$ subunit of oncogenic mucin 1 (MUC1-C) protein, which induces ZEB1 expression in a nuclear factor kappa B (NF-kB) p65-dependent manner, can

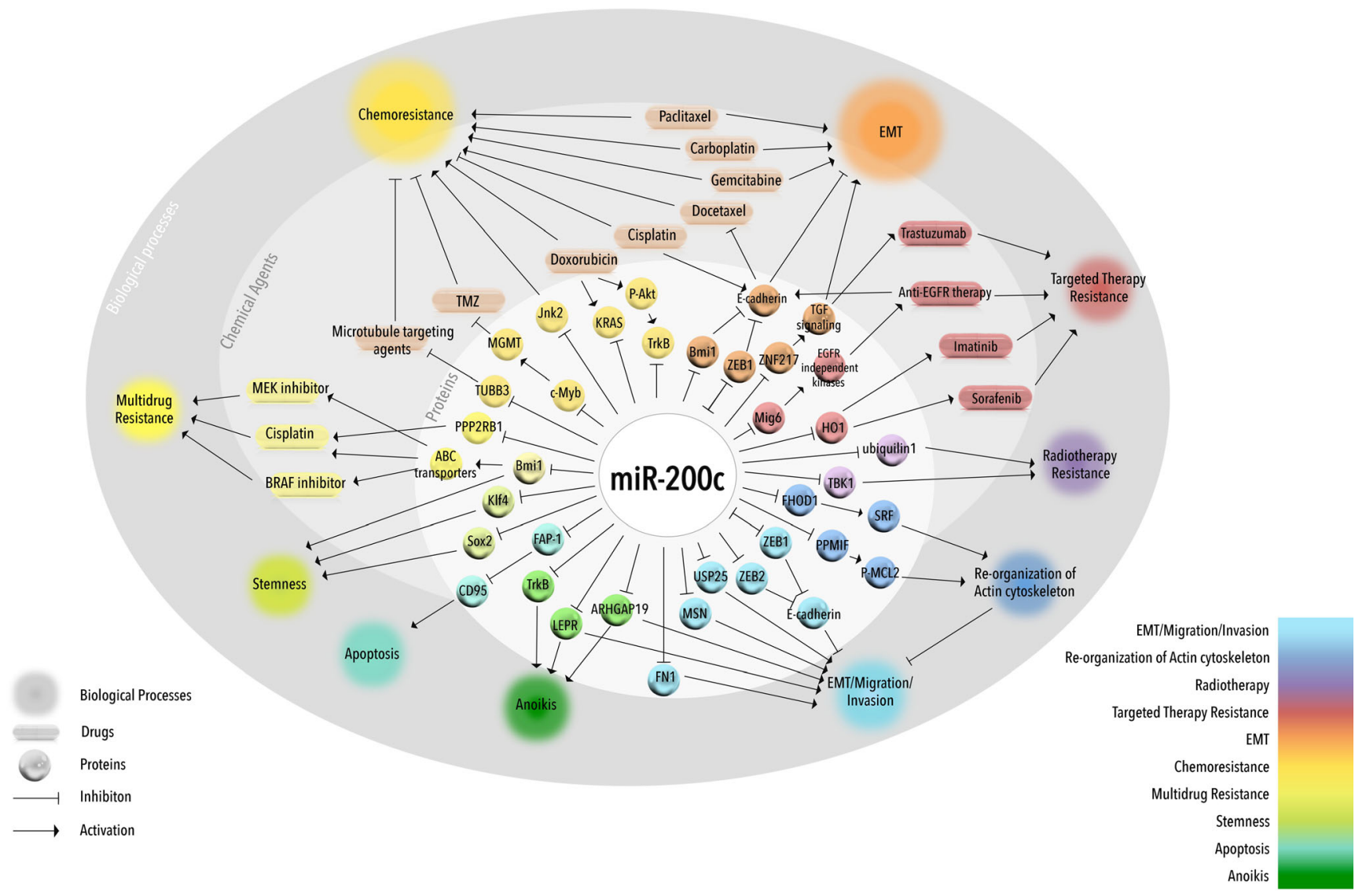

Fig. 2 miR-200c regulates EMT and drug resistance. Graphical representation of miR-200c-mediated regulation of EMT and drug resistance via direct or indirect targeting of several proteins involved in EMT and multiple drug resistance mechanisms 
transcriptionally suppress miR-200c by forming a repression complex with ZEB1 and thus can regulate subsequent induction of EMT [40] (Fig. 2).

\section{miR-200c inhibits EMT via regulating targets other than ZEB1/2}

Despite its importance, E-cadherin restoration is not always enough for the inhibition of migration and invasion potential of cancer cells; however, it has been shown that miR-200c expression, alone, is enough to inhibit EMT, migration, and invasion which suggests the involvement of other direct targets of miR-200c as EMT regulators [41]. A recent study has suggested miR-200c-mediated repression of protein kinase A subunits as the underlying mechanism of miR-200c-mediated inhibition of migration in breast cancer cells [42]. This effect of miR-200c has also been linked to its targeting of ubiquitinspecific peptidase 25 (USP25) in non-small-cell lung cancer (NSCLC) [43]. In addition, we have demonstrated that miR200c directly targets actin cytoskeleton regulatory proteins, FHOD1 and PPM1F, and represses migration and invasion of breast cancer cells in a ZEB1/2/E-cadherin-independent manner [41]. Importantly, several molecules linked to cell motility, such as FN1, moesin, neurotrophic tyrosine receptor kinase type 2 (NTRK2 or TrkB), leptin receptor (LEPR), and Rho GTPase-activating protein 19 (ARHGAP19), are among the direct targets of miR-200c, and in aggressive breast and endometrial cancer cells which lack miR-200c, aberrant expression of these targets contributes to the EMT phenotype [44] (Fig. 2). Moreover, not only ZEB2 but also other proteins in ZEB2 and Snail1 transcriptional repressor complexes such

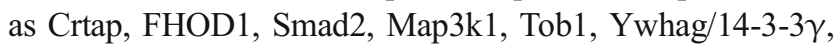
Ywhab/14-3-3ß, Smad5, Zfp36, Xbp1 and Mapk12 are also among the direct targets of miR-200c [45].

Cyclin-dependent kinase inhibitor, p21, is also capable of blocking EMT [46] whereas loss of p21 induces EMT and downregulates several miRNAs, including miR-200c, in a colorectal cancer cell line. Interestingly, overexpression of miR-200c, alone, in these p21-deficient cells inhibited EMT, migration, and invasion [47]. miR-200 family miRNAs are usually repressed in cells subjected to EMT progression. For example, cells, which underwent EMT in response to transforming growth factor beta (TGF- $\beta$ ) or to ectopic expression of protein tyrosine phosphatase, Pez, show decreased levels of miR-200 family miRNAs [48]. Using a mouse model system, another study has also shown that TGF- $\beta$-mediated EMT progression is indeed correlated with downregulation of miR-200 family miRNAs in mammary epithelial cells [34]. Overall, these studies suggest that both the regulation and regulatory effects of miR-200c are critical determinants in initiating EMT and pursuing the subsequent steps in metastatic cascade.

\section{Role of miR-200c in therapy resistance}

In addition to regulation of EMT and metastasis, miR-200 family, in general, and miR-200c, in particular, also take part in regulating therapy resistance. For instance, a recent study with tissue samples from esophageal cancer patients receiving neoadjuvant chemotherapy has clearly shown an inverse correlation between miR-200c expression and sensitivity toward chemotherapeutic agents. The underlying mechanism is proposed to be enhanced activation of the PI3K/Akt pathway, which is preceded by downregulation of a subunit of protein phophatase $2 \mathrm{~A}$, PPP2R1B, a negative regulator of Akt phosphorylation. PPP2R1B is a direct target of miR-200c; therefore, its downregulation through upregulated miR-200c results in the activation of the PI3K/Akt pathway and subsequent resistance against cisplatin [49] (Fig. 2). In addition, higher levels of circulating miR-200c have been observed in patients of castration-resistant prostate cancer (CRPC), particularly, in those showing resistance to docetaxel. Despite this seemingly negative correlation between miR-200c levels and drug sensitivity in patients, most of the in vitro studies suggest an opposite link and present miR-200c as an inducer of sensitivity against anti-cancer agents. This discrepancy may be due to the influence of non-tumor cells on the levels of circulating miR-200c as well as the regulatory effects of the tumor microenvironment on cancer cells at the primary tumor site [50]. Several targets of miR-200c are known to play important roles in mediating multidrug resistance, chemo-sensitivity and chemo-resistance, and targeted therapy resistance as well as response to radiotherapy.

\section{miR-200c and multidrug resistance}

The role of miR-200c in multidrug resistance was first demonstrated in relation to ATP-binding cassette (ABC) transporters (Fig. 2), the largest transmembrane protein family, responsible for resistance against multiple drugs. In general, overexpression of $\mathrm{ABC}$ transporters creates increased drug efflux, resulting in a decreased intracellular drug deposition and a subsequent acquisition of resistance against the given therapy [51]. miR-200c has been shown to play an active role in limiting $\mathrm{ABC}$ transporter-mediated multidrug resistance in melanoma as its ectopic expression in these cells was able to downregulate $\mathrm{ABC}$ transporters: $\mathrm{ABCG} 2, \mathrm{ABCG} 5$, and multi-drug resistance gene (MDR1). The underlying effect is attributed to direct targeting of Bmil by miR-200c, and knocking down Bmil in these cells results in lower $\mathrm{ABC}$ transporter levels and higher sensitivity to a DNA-damaging agent cisplatin, as well as to a BRAF and a MEK inhibitor (PLX4720 and U0126, respectively) [52]. Being a member of polycomb group proteins, Bmil is reported to be upregulated in various cancers and is associated with a more aggressive 
disease progression and cancer stemness [53]. From these findings, miR-200c seems to be an important player during multidrug resistance considering the pivotal role of $\mathrm{ABC}$ transporters in mediating chemoresistance in a wide variety of cancers.

\section{miR-200c and chemotherapy resistance}

Overexpression of miR-200c has been shown to enhance the response to several chemotherapeutic agents in various cancer types. In melanoma cells, miR-200c overexpression results in increased sensitivity to cisplatin [52] (Fig. 2). In endometrial and ovarian cancers, miR-200c increases taxane sensitivity by targeting class III B-tubulin gene (TUBB3), which is known to be a mediator of resistance against microtubule-targeting agents $[54,55]$. A recent study, encompassing a panel of ovarian adenocarcinoma cell lines, has also shown the inhibitory action of miR-200c on TUBB3 expression, which also depends on the nuclear localization of an RNA-binding protein, HuR [56]. Another study revealed that decitabine treatmentdependent upregulation of miR-200c and miR-141 promotes epithelial-like characteristics in highly invasive oxaliplatinresistant colorectal cancer cells [57].

On the other hand, loss of miR-200c has been shown to be associated with acquisition of resistance against various chemotherapeutic agents in different cancer types. Doxorubicin treatment of a breast cancer cell line, BT474, results in decreased miR-200c level, which ultimately leads to an increase in KRAS, a direct target of miR-200c. This study suggests miR-200c as an important checkpoint for the development of chemoresistance mediated through activation of an important oncogenic pathway [58]. In recurrent and metastatic colorectal cancer, miR-200c expression is suppressed, and its overexpression attenuates the JNK signaling pathway resulting in an increased sensitivity of resistant cells to several chemotherapeutic agents and a subsequent decrease in their metastatic potential in both in vitro and in vivo models. Furthermore, miR-200c level is inversely correlated with JNK2, ABCB1, and MMP-9, which are the downstream targets of the JNK pathway, and this negative correlation may be used as a predictive marker of therapeutic outcome in these patients [59]. In two different breast cancer cell lines, resistance against doxorubicin is correlated with marked inhibition of miR-200c where TrkB has been suggested as the key target of miR-200c in regulating this resistance [60]. TrkB plays important roles in differentiation, in proliferation, and mostly, in cell survival mediated through PLC, MAPK, or PI3K/Akt signaling in neurons [61]. Notably, TrkB has also been found to be associated with drug resistance in neuroblastoma [62, 63] and head and neck squamous cell carcinoma [64]. Interestingly, TrkB downregulation after ectopic expression of miR-200c in doxorubicin-resistant breast cancer cells sensitizes the cells toward doxorubicin treatment. Furthermore,
TrkB expression has been correlated with the phosphorylation status of Akt in miR-200c-treated doxorubicin-resistant cells where low p-Akt level has been observed with a concomitant decrease in TrkB protein level [60]. All in all, these studies propose possible mechanisms to explain the multi-factorial nature of a given miRNA (here: miR-200c) in mediating the response of cancer cells against different types of chemotherapy.

\section{miR-200c and targeted therapy resistance}

Besides regulating chemotherapy resistance, miR-200c also takes part in mediating targeted therapy resistance (Fig. 2). In a microarray-based study on tamoxifen-sensitive MCF-7 and tamoxifen-resistant LY2 breast cancer cell lines, several novel miRNAs including miR-200c were found to be differentially expressed between sensitive and resistant cells [65]. In a later study by the same group, it has been shown that ectopic expression of miR-200c in endocrine-resistant LY2 cells has significant effect on enhanced sensitivity to fulvestrant, but not to tamoxifen [66]. Targeting the MAPK pathway is a current treatment option for metastatic melanoma patients; however, nearly $50 \%$ of the patients receiving BRAF and MEK inhibitors develop resistance within 6-7 months following treatment initiation. Overexpression of miR-200c also significantly enhanced the anti-proliferative effects of both PLX4720, a specific BRAF inhibitor, and trametinib, a selective inhibitor of MEK1/2 kinase, in melanoma cells [67] suggesting a potential anti-MAPK therapy sensitizer role for miR-200c.

Reduced miR-200c and subsequent increase in its target genes such as Bmil, ZEB2, TUBB3, ABCG5, and MDR1 have also been shown to promote acquisition of BRAF inhibitor resistance in melanoma. Therefore, these genes could be potential therapeutic targets against development of BRAF inhibitor resistance [68]. In sorafenib- and imatinib-resistant renal cell carcinoma cells, heme oxygenase 1 (HO1) has been found to be a direct target of miR-200c. This enzyme is induced during oxidative stress, and its overexpression following a decrease in miR-200c level in resistant cells is found to be partially responsible for drug resistance by inhibiting apoptosis and autophagy [69]. Exploring druggable targets of miR-200c responsible for conferring drug resistance may help in shaping the strategies to improve the efficacy of chemotherapy and targeted therapy.

\section{miR-200c and radiotherapy resistance}

The first line of evidence regarding association between miR$200 \mathrm{c}$ and radiotherapy resistance came from a study on breast cancer cells where low levels of miR-200c expression were correlated with radio-tolerance, and ectopic miR-200c expression enhanced the (IR)-induced apoptosis by directly targeting 
TANK-binding kinase 1 (TBK1) [70] (Fig. 2). Recently, another target of miR-200c, ubiquilin 1, has been shown to positively regulate radio-resistance by enhancing IR-induced autophagy in MDA-MB-231 breast cancer cells. Ectopic expression of miR-200c reversed the phenotype and sensitized the cells to radiation [71]. Furthermore, nanoparticle-assisted delivery of miR-200c has been shown to inhibit CSC-like properties and to augment radiosensitivity in three different gastric cancer cell lines [72]. Altogether, miR-200c-assisted/conjugated therapies (chemotherapy, targeted therapy, and radiotherapy) may have greater potential to overcome radiotherapy resistance and to limit escape mechanisms in multiple cancer types.

\section{miR-200c at the intersection of EMT and drug resistance}

Over the last decade, several lines of evidence show that EMT might render the cells resistant against the implemented anticancer therapy supporting the notion that EMT and therapy resistance go hand in hand [73]. In addition, involvement of miRNAs in combined regulation of drug resistance and EMT is evident [74]. Likewise, miR-200c, a negative regulator of EMT, has shown great potential to overcome both chemotherapy and targeted therapy resistance through reversing the EMT process or promoting epithelial-like state (Fig. 2).

\section{miR-200c, EMT, and chemotherapy resistance}

Platinum-based chemotherapeutic agents, e.g., cisplatin, are being used as first line treatment for NSCLC, but resistance to these agents is inevitable. In highly aggressive cisplatinresistant NSCLC cells, miR-200c is lost due to promoter hypermethylation, and forced introduction of $\mathrm{miR}-200 \mathrm{c}$ induces loss of mesenchymal features, which reverses the resistance against cisplatin [75]. In addition, upregulation of several EMT markers including ZEB1/ZEB2 and downregulation of epithelial marker, E-cadherin, are identified as the characteristic features of docetaxel-resistant prostate cancer cells, and the underlying mechanism again correlates with decreased miR-200c expression [76] (Fig. 2). Furthermore, gemcitabine-resistant pancreatic cancer cells showed EMT features along with low miR-200a, miR-200b, and miR200 c levels. Upregulation of these miRNAs upon treatment with two natural agents, 3,3'-diindolylmethane and isoflavone, reversed the EMT phenotype [77]. Moreover, the anticancer effects of an anti-diabetic drug, metformin, have been associated with downregulation of several CSC markers, such as CD44 and EPCAM in pancreatic cancer, which, in turn, linked with re-expression of several miRNAs including miR-200c in gemcitabine-sensitive and gemcitabine resistant cells [78]. Similarly in pancreatic CSCs, decrease in chemoresistance has been attributed to overexpression of miR-200c [79]. In addition, miR-200c together with other miRNAs from the miR-200 family has been shown to sensitize ovarian cancer cell lines with strong EMT phenotype to anti-cancer drugs paclitaxel and carboplatin [80].

Although miR-200c-mediated attenuation of chemoresistance is mainly associated with reversal of the EMT process, underlying mechanisms are not restricted to the canonical miR-200c/ZEB1/E-cadherin axis but involve other miR-200c targets as well. For instance, in glioblastoma cells, ectopic ZEB1 expression decreased the sensitivity to chemotherapeutic agent, temozolomide (TMZ), in vitro while ZEB1 knockdown resulted in opposite effects in both in vitro and in vivo. ZEB1 was found to be co-localizing with a major chemoresistance enzyme, MGMT, at the edges of glioblastoma xenograft tumors where cells are more invasive and chemoresistant. In principle, increased ZEB1 level in these cells blocks miR-200c expression and subsequently upregulates c-Myb transcription factor (a direct target of miR-200c) which, in turn, activates MGMT transcription resulting in attenuation of anti-proliferative effects of TMZ [81]. Interestingly, a recent study on breast cancer lung metastasis has shown that EMT is dispensable for lung metastasis, but miR-200-mediated reversal of EMT helps in sensitizing metastatic cells to chemotherapeutic drug cyclophosphamide [82]. These results indicate the importance of miR-200c as a key element in determining the fate of chemoresistant cancer cell via regulating EMT.

\section{miR-200c, EMT, and targeted therapy resistance}

Association of miR-200c-mediated inhibition of EMT with targeted therapy resistance has been established through several studies. In particular, resistance against anti-EGFR therapies (e.g., cetuximab, gefitinib, erlotinib, etc.) has been demonstrated to be tightly linked with acquisition of EMT phenotypes proceeded by the loss of miR-200c in various cancer types. For instance, in urothelial carcinoma cells, showing mesenchymal-like features and exhibiting resistance against anti-EGFR therapies, a complete reversal of resistance could be acquired with the introduction of miR-200c and subsequent downregulation of ZEB1/2 and upregulation of E-cadherin [83]. In gefitinib-resistant EGFR-mutant lung cancer cell lines, low miR-200c expression due to DNA hypermethylation was found to be correlated with EMT features characterized by increased ZEB1 and decreased E-cadherin levels in these cells [84]. Likewise, reversal of cetuximab resistance by miR-200c is accompanied by the loss of EMT features in highly invasive and aggressive NSCLC cells [75]. Similarly, reversal of erlotinib resistance in EGFR-mutant NSCLC xenografts treated with a potent natural agent, silibilin, is associated with the loss of EMT-related features including low miR-200c and E-cadherin and high ZEB1, Snail, and N- 
cadherin expression [85]. However, in a similar study with erlotinib-resistant lung adenocarcinoma cells, overexpressed miR-200c regulates expression of EMT network proteins resulting in a slight increase in erlotinib sensitivity. Furthermore, a TGF- $\beta 1$-responsive element is identified at the promoter region of miR-200c, which suggests the suppression of miR-200c in a Smad3/4-dependent manner at the downstream of activated TGF- $\beta$ signaling. Interestingly, TGF- $\beta 1$ is also not able to fully induce EMT and to cause significant changes in erlotinib response in these cells [86]. Therefore, further understanding of the effects of TGF- $\beta$ signaling on miR-200c-mediated EMT and anti-EGFR resistance could provide more details about the importance of the tumor microenvironment in controlling miRNA expression and response to targeted therapies.

Recently, a study in the context of the TGF- $\beta / \mathrm{miR} 200 \mathrm{c}$ axis explored that prolonged exposure to TGF- $\beta$ not only facilitates EMT but also makes cells undergo EMTassociated kinase switch, which results in EGFR inhibitor resistance characterized by decrease in miR-200c levels and upregulation of one of its direct targets, Mig6/ERRFI-1. Mig6 is a negative regulator of the EGFR family, and its overexpression increases the internalization of EGFR and thereby reduces its localization to the surface. Despite having lower EGFR activation, cells overexpressing Mig6 show higher Akt phosphorylation through activation of EGFRindependent tyrosine kinases and thereby increase their survival. Furthermore, elevated Mig6/miR-200c ratio is found to be associated with erlotinib resistance in a panel of 25 tumor cell lines and in patient-derived xenografts (PDXs) of NSCLC and pancreatic cancer [87]. Introduction of miR-200c to bladder cancer cells results in complete reversal of resistance against anti-EGFR therapies mainly through Mig6 downregulation, which in turn leads to increased surface levels of EGF receptors, thus making the anti-EGFR therapy more effective in inhibiting the signal [83]. Recently, a feedback loop between miR-200c and TGF- $\beta$ pathway was discovered in which miR-200c can regulate TGF- $\beta$ signaling by directly targeting ZNF217, a transcriptional activator of autocrine TGF- $\beta$. Elevated TGF- $\beta$ signaling leads to increased invasiveness as well as trastuzumab resistance (Fig. 2). In trastuzumabresistant breast cancer cells, miR-200c was found to be the most significantly downregulated miRNA, and its ectopic expression decreases invasiveness and increases trastuzumab sensitivity through downregulation of ZNF217. Besides ZNF217, ZEB1 expression was also shown to be significantly upregulated in trastuzumab-resistant cells. Double knockdown of ZEB1 and ZNF217 decreased invasiveness and partially restored trastuzumab sensitivity. Furthermore, miR-200c treatment of xenografts of a trastuzumab-resistant breast cancer cell line leads to re-gain of trastuzumab sensitivity [88]. In the same scenario, another level of regulation comes from a long non-coding RNA, Lnc-ATB, which is expressed at the downstream of TGF- $\beta$ signaling and competitively binds to miR-200c conferring ZEB1 and ZNF217 (upregulation)-mediated trastuzumab resistance [89]. In summary, these studies clearly provide the cue that miR-200c could efficiently control the response of cancer cells to anti-cancer therapies through EMT-dependent and EMT-independent pathways.

\section{miR-200c regulation of signaling pathways}

Over the years, it has been well established that miR-200c plays critical roles in regulating multiple biological processes and signaling cascades varying from MAPK signaling, to Notch signaling, to TLR signaling (Fig. 3). In the context of developmental program, miR-200c has been found to accumulate in epithelial buds in developing submandibular glands and control FGFR-mediated epithelial proliferation by targeting vldlr and its ligand reelin which regulate FGFR signaling in these cells [90]. Furthermore, miR-200c-mediated activation of BMP signaling via upregulation of amelogenin and E-cadherin and via downregulation of noggins triggers tooth development and renewal through dental epithelial cell differentiation in mice [91].

IGF-induced PI3K/Akt and MAPK signaling can enhance EMT and metastasis by downregulating miR-200c levels in gastric cancer, which can be restored by Cbl-b-mediated ubiquitination of IGF-IR [92] (Fig. 3). Recent data showed that miR-200c negatively regulates KRAS as well, resulting in inhibition of both PI3K/Akt and MAPK pathways in breast and lung cancer cells $[58,93]$. TGF- $\beta$-induced expression of ZEB transcription factors downregulates miR-200c resulting in reduced EGFR activity due to upregulation of Mig6 and confers EMT [87]. On the contrary, TGF- $\beta$-induced upregulation of miR-200c has been shown in diabetic nephropathy where miR-200c targets FOG2, which is a negative regulator of the PI3K/Akt pathway [94]. miR-200c also suppresses TGF- $\beta$ signaling by targeting ZNF217 in breast cancer cells, an indirect mechanism to target ZEB-induced metastasis [88].

In addition to the well-characterized role of miR-200 family miRNAs in the regulation of EMT, miR-200c has been widely reported to take part in controlling tumor progression either by regulating or being regulated by different signaling mechanisms. Regarding cell death signaling, miR-200c sensitizes breast cancer cells to aniokis by targeting NF-KBinduced TrkB and NTF3 [44, 95] and enhances Fasassociated apoptosis by targeting FAP-1 in different cancer cell types [96] (Fig. 3). Additionally, in triple negative breast cancer (TNBC), miR-200c has been shown to enhance apoptosis by directly targeting X-linked inhibitor of apoptosis (XIAP) which serves as E3 ubiquitin ligase and degrades caspases essential for apoptosis [97]. In undifferentiated human ESCs, miR-200c is upregulated, and its knockdown downregulates Nanog expression and enhances 


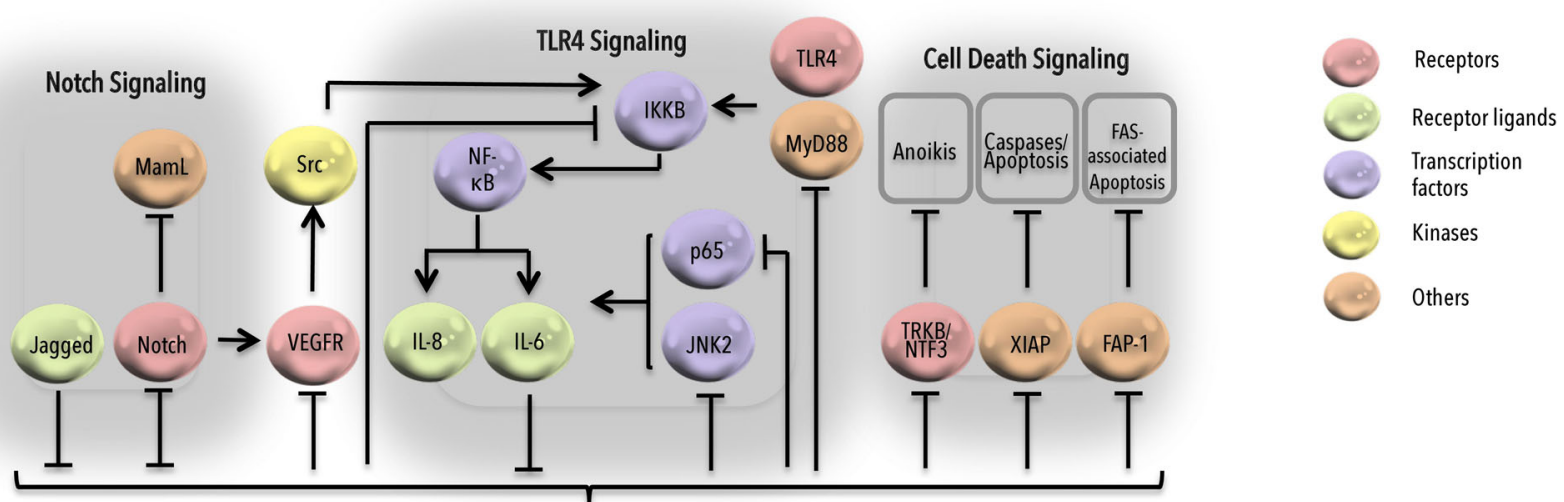

\section{miR-200c}

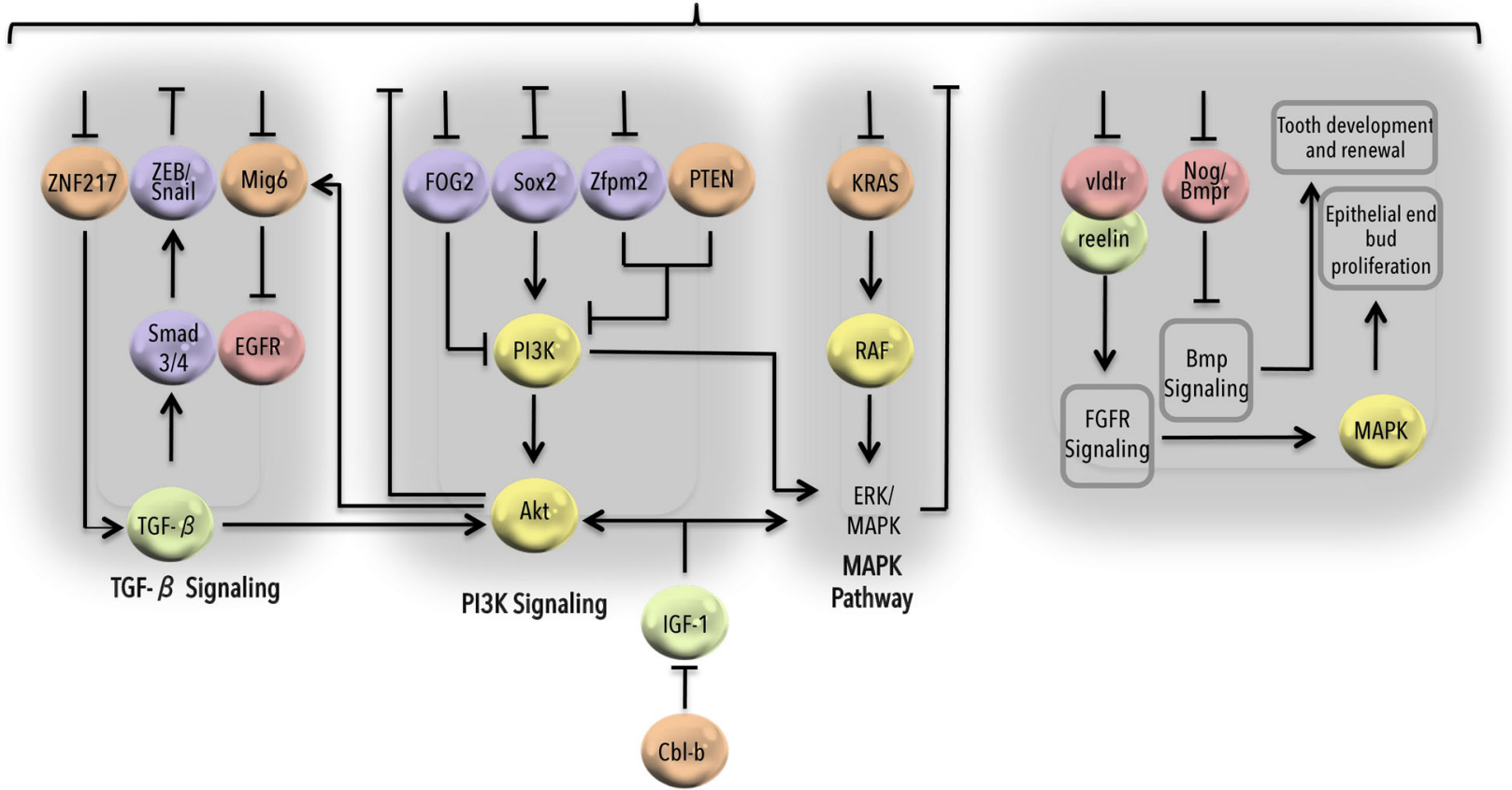

Fig. 3 miR-200c in signaling pathways. Graphical representation of involvement of miR-200c in multiple signaling cascades and their cross-talk

GATA4 levels resulting in apoptosis [98]. Furthermore, Oct4 and Sox 2 can bind to miR-200c promoter and enhance MET and induce pluripotent stem cell development by suppressing ZEB2 [23]. miR-200c was found to be downregulated in normal mammary progenitor cells and breast CSCs. When overexpressed, it targets Bmil, a known regulator of stem cell self-renewal, and suppresses the mammary duct formation ability of mammary stem cells and tumor growth driven by breast CSC [36]. In colorectal cancer, miR-200c regulates stemness by targeting Sox 2 in a double negative feedback loop, and loss of miR-200c resulted in enhanced expression of stem cell markers (CD166, CD133, and beta-catenin) downstream of Sox2. In the same study, miR-200c-Sox 2 feedback loop has also been shown to regulate the PI3K/Akt pathway and control the proliferative and metastatic potential of colorectal cancer via phosphorylation of PI3K by Sox2 [99]. On the contrary, in pancreatic and ovarian cancer, miR-200c has been shown to be directly targeting Zfpm 2 and indirectly reducing Pten levels, both of which are negative regulators of the PI3K/Akt pathway [100, 101].

Notch signaling determines accurate growth and development of various tissues and organs, and its aberrant activation may lead to cancer. Overexpressing miR-200c in metastatic prostate cancer impedes proliferative potential of cancer cells by directly targeting Jagged1 receptors involved in Notch signaling [102] whereas overexpression of Notch1 decreases miR-200c levels in pancreatic cancer [103] (Fig. 3). Notch also activates truncated isoform of Flt1/VEGFR-1 (which is downregulated in the presence of miR-200c [104] and of importance in angiogenesis-associated VEGF signaling) leading to activation of proto-oncogene Src, which cross talks with and downregulates miR-200c in an NF-KB/IL-6-dependent manner [105]. miR-200c regulates TLR4/MyD88-dependent activation of NF- $\mathrm{kB}$ by directly targeting MyD88. 
Interestingly, TAB2, TRAF6, and IRAK1, at the upstream of NF- $\kappa$ B activation in TL4/MyD88 and TNF- $\alpha$ signaling, are also among the potential targets of miR-200c depicting multistep targeting of signaling components by miRNAs [106]. In breast cancer cells, MUC1-C induces EMT by upregulating ZEB1 in an NF-kB/p65-dependent manner and downregulating miR-200c by making a complex with upregulated ZEB1 [40]. IL-6-mediated suppression of miR-200c led towards activation of its downstream targets JNK2 and p65 (required for constitutive activation of IL-6) whereas loss of IL-6 in a mouse model impaired tumorigenicity due to activation of miR-200c [107]. Overexpressing miR-200c also controls inflammation-associated IL- 8 in leiomyoma (smooth muscle tumor) by targeting IKKB at the upstream of NF- $\mathrm{KB}$, thus decreasing p65 binding at IL-8 promoter [108]. Overall, in addition to playing important roles in EMT and metastasis, miR-200c has been adapted to regulate multiple normal growth, development, cancer, and other diseases.

\section{miR-200c as a biomarker}

Similar to proteins, expression level of individual or group of miRNAs has been suggested to be utilized as biomarkers to predict disease progression, diagnosis, and treatment response. In this scenario, dysregulated expression of miR200c in multiple cancer-related mechanisms, which we have discussed here, is enough to support its use as a biomarker, at least in cancer. miR-200c can both be (i) an intracellular marker in tissues (cancer and normal) and (ii) an extracellular marker in body fluids (blood, urine) as free molecules or secreted in exosomes (Table 1).

As an intracellular marker, significantly downregulated miR-200c together with downregulation of miR-335 and miR-218 and upregulation of miR-122, miR-155, and miR210 has been anticipated to be used as a potential biomarker of pathogenesis for clear cell renal cell cancer [120]. In addition, miR-200c has been suggested as predictor of survival and biomarker of relapse in stage I epithelial ovarian cancer patients [119]. In Caucasian and Asian intrahepatic cholangiocellular carcinoma (ICC) patients, miR-200c downregulation resulted in enhanced EMT which led towards increased cell motility and invasion capacity of ICC as well as induced hepatic stem cell-like gene expression pattern, such as NCAM1 upregulation [111]. In bladder cancer, low levels of miR-200c along with miR-141 and miR-30b are associated with poor prognosis [123]. In TNBC, reduced expression of miR-200c along with miR-205 has been found to be significantly associated with lymph node metastasis [124]. Recently, it has been revealed that miR-200c levels are inversely correlated with advanced clinical stages and lymph node metastasis of ovarian cancer [47]. In intraductal papillary mucinous neoplasm (IPMN), the high-grade tumors were demonstrated to have EMT characteristics such as low E-cadherin and high vimentin and ZEB1 levels. Furthermore, miRNA array analysis identified miR-200c and miR-141 to be downregulated in malignant tumors as compared to low-grade IPMN tumors. This underpins the importance of the miR-200c-ZEB1 pathway in the progression of IPMN and presents it not only as a prognostic biomarker but also as a potential target for IPMN therapy [113].

In addition to EMT and metastasis, miR-200c expression has potential to predict therapy resistance as well. Ovarian and breast cancer patients showing incomplete response to paclitaxel treatment expressed low levels of miR-200c along with significant increase in beta-tubulin and ZEB1 expression when compared with patients showing complete response to paclitaxel [109, 118]. Furthermore, in NSCLC patients, high expression of miR-200c has been found to be correlated with bigger tumor size and worse overall survival suggesting an oncogenic activity of miR-200c [114, 115]. In terms of tumor subtype classification, oncocytoma and chromophobe structures in renal tumors can be distinguished according to miR200c and miR-139-5p expression patterns [121]. Moreover, miR-200c together with differential expression of other miRNAs is a candidate to distinguish hepatocellular carcinoma (HCC) from intrahepatic cholangiocarcinoma [112].

Besides its potential to be used as a biomarker in tissues, miR-200c level in serum as circulating miRNA has also been proven to be a promising prognostic and diagnostic factor for several diseases including various cancer types. For instance, increased levels of circulating miR200 family members in serum have been shown to be associated with serous epithelial ovarian cancer (SEOC) [131] (Table 1). High level of miR-200c in sera of ovarian [134] and esophageal cancer patients [135] is also correlated with poor prognosis. Furthermore, presence of miR200c in patients' sera as circulating miRNA has been validated as a diagnostic marker for gastric cancer [127]. miR-200c has been shown as a significant predictor of tumor stage in colorectal cancer as high level of this miRNA in serum is able to significantly discriminate stage IV from stage I-III colorectal cancer patients. In addition, these high serum levels are positively correlated with lymph node metastasis, distant metastasis, poor prognosis, and tumor recurrence in colorectal cancer [125]. Similarly, in prostate cancer, together with four other circulating miRNAs, elevated levels of miR-200c have been shown to be higher in sera taken from patients with metastatic castration-resistant prostate cancer as compared to healthy controls [132]. Dysregulated level of miR-200c in serum has also been observed in non-cancer diseases such as Crohn's disease [126] and Kawasaki disease [128] which further proves its fate as a diagnostic biomarker.

Circulating tumor cells (CTCs), on their own, are shown to be indicators of cancer metastasis, but are 
Table $1 \mathrm{miR}-200 \mathrm{c}$ as a biomarker

\begin{tabular}{|c|c|c|c|}
\hline Biomarker & Disease & Status & Reference \\
\hline \multicolumn{4}{|c|}{ Intracellular marker } \\
\hline \multirow[t]{9}{*}{ Tissues } & Breast cancer & Paclitaxel treatment response & [109] \\
\hline & Colorectal cancer & Metastasis & {$[110]$} \\
\hline & $I C C$ & $\begin{array}{l}\text { Diagnosis, subtype Classification, } \\
\text { EMT }\end{array}$ & {$[111,112]$} \\
\hline & $I P M N$ & Malignancy, EMT & {$[113]$} \\
\hline & Non-small cell lung cancer & $\begin{array}{l}\text { EMT, metastasis, Gemcitabine } \\
\text { drug response }\end{array}$ & [114-117] \\
\hline & Ovarian cancer & Paclitaxel treatment response & [118] \\
\hline & Epithelial ovarian cancer & Patient survival & [119] \\
\hline & Renal cell carcinoma & $\begin{array}{l}\text { Diagnosis, prognosis, metastasis, } \\
\text { subtype classification }\end{array}$ & {$[120-122]$} \\
\hline & Bladder cancer & Prognosis & [123] \\
\hline CTCs & Breast cancer & Metastasis & {$[124]$} \\
\hline \multicolumn{4}{|c|}{ Extracellular marker } \\
\hline \multirow[t]{9}{*}{ Serum } & Breast cancer & Metastasis (via CTC) & {$[50]$} \\
\hline & Colorectal cancer & Prognosis, metastasis & {$[125]$} \\
\hline & Crohn's disease & Diagnosis & [126] \\
\hline & Gastric cancer & Diagnosis, prognosis & {$[127]$} \\
\hline & Kawasaki disease & Diagnosis & [128] \\
\hline & Lung cancer & Prognosis & [129] \\
\hline & Ovarian cancer & Diagnosis (via exosomes) & {$[130]$} \\
\hline & SEOC & Diagnosis & {$[131]$} \\
\hline & Prostate cancer & Metastasis & [132] \\
\hline Urine & Chronic kidney diseases & Diagnosis (via exosomes) & {$[133]$} \\
\hline
\end{tabular}

Diseases and their status related to miR-200c expression are listed with the location where significant miR-200c expression has been detected to be used as a biomarker

ICC intrahepatic cholangiocarcinoma, IPMN intraductal papillary mucinous neoplasm, CTC circulating tumor cells, SEOC serous epithelial ovarian cancer difficult to detect [136]. Deep miRNA-array analysis of circulating miRNAs in the sera of metastatic breast cancer patients and healthy controls has demonstrated that miR-200c levels were significantly higher in CTCpositive patients compared to CTC-negative patients and healthy controls suggesting a role for circulating miRNAs in predicting CTC status and associated metastatic disease [50].

miRNAs are not only circulating in extracellular fluids, but they are also secreted from tissues to their extracellular environment in exosomes. For instance, levels of miR$200 \mathrm{c}$ and seven other miRNAs in tumor-secreted exosomes were found to be similar to those in ovarian tumor cells confirming diagnostic potential of profiling circulating tumor exosomes [130]. Furthermore, exosomal secretion of miR-200c in urine has been observed in various chronic kidney diseases [133] and in systemic diseases such as lupus [137]. As a whole, miR-200c has a huge potential to be used as a biomarker of diagnosis, disease progression, and predicting treatment response.

\section{Future perspectives}

The role of miR-200 family, especially miR-200c, in regulating cancer metastasis and acquisition of drug resistance, two major interlinked hallmarks of cancer, has been very well established. However, a new insight came from a recent study in breast cancer where miR-200 overexpression has been shown not to affect onset of lung metastasis but to increase post-metastatic chemosensitivity suggesting the potential of miR-200-based EMT-targeting strategy in enhancing chemosensitivity [82]. Further understanding of underlying mechanisms will help improve and re-shape future EMTtargeting strategies.

With the advances in the field of non-coding RNAs over the last decade with the help of technological advancements in deep sequencing, researchers have now started focusing on the interactions among various kinds of non-coding RNAs, e.g., long intergenic RNAs, circular RNAs and miRNAs, etc., to understand the developmental and disease-associated mechanisms. Recently, a long non-coding RNA named ATB 
has been shown to be activated downstream of TGF- $\beta$, which competitively binds to miR-200 family in HCC cells, upregulates ZEB1/2 transcription factors, and induces EMT [138]. Therefore, future research on miR-200c function should also include lncRNAs, in addition to proteins, to have a better understanding of its mechanism of action.

Importantly, cell-cell interaction via exosome transport within the tumor microenvironment is of great importance in maintaining tumor state and developing drug resistance. In this line, pre-treatment of A549 cells with exosomes collected from cisplatin-treated counterparts decreased miR-200c expression along with altering the expression of different miRNAs [139]. Untangling the puzzles of the tumor microenvironment will further improve our knowledge about involvement of miR-200c and its trafficking in regulating tumor state.

Tumor suppressor miRNAs, like miR-200c, have potential to be used as therapeutic agents, but their delivery and stability in body fluids is of great concern. Major challenges include (1) poor penetration of miRNAs in tumor tissues, (2) miRNA degradation in body fluids, (3) miRNA-associated immunotoxicity and neurotoxicity, (4) inefficient gene silencing due to poor intracellular delivery of miRNAs, (5) off-target effects, and (6) unavailability of sufficient miRNA-processing enzymes. Multiple miRNA modification techniques have been described to better overcome these barriers (reviewed in [140]). For example, targeted delivery of aptamerconjugated let-7g in a xenograft model of lung adenocarcinoma has shown promising results in reducing tumor growth [141]. In addition, combining miRNAs with other therapy agents is another option to better utilize miRNAs as therapeutic tool. For instance, miR-200c has been found to increase the radiosensitivity by directly regulating oxidative stress response genes PRDX2, GAPB/Nrf2, and SESN1 which led to the inhibition of DNA double-strand break repair, increased levels of reactive oxygen species, and upregulated p21 [142].

Recently, miR-34, a well-known tumor suppressor miRNA that is in a double-negative feedback loop with Snail, like miR-200c and ZEB1, has been entered in a phase-I clinical trial (NCT01829971) for the treatment of HCC [143]. Furthermore, regarding the control of multiple oncogenes in different tumor tissues, miR-200c can be considered as a promising targeted therapy molecule similar to miR-34a. Therefore, a broad range of tumor suppressor functions conducted by miR-200c reviewed here also need to be assessed in clinical trials for the benefit of patients using miR-200c-based therapeutics.

\section{Concluding remarks}

Regulation of gene expression by miRNAs is not to serve just as a switch - turning protein production on or off-but to fine-tune the overall gene expression output providing robustness to cell-specific programs. In this article, we reviewed miR-200c, a well-established, exceptional miRNA, which fine-tunes gene regulation in various diseases, especially in cancer. Notably, miR-200c simultaneously regulates major elements of cancer progression, i.e., proliferation, EMT, and drug resistance, in a context-dependent manner. Commonly known mesenchymal transcription factors ZEB1 and ZEB2 are among the direct targets of miR-200c; thus, it has established a strong link with EMT regulation. In addition, miR-200c is also correlated with and regulates chemoresistance, multidrug resistance, targeted therapy resistance, radiotolerance, and stemness through targeting and modulating the activities of key molecules involved in these processes. Overall, miR-200c functions at the crossroad of EMT and drug resistance reversal and has great potential to be used as therapy sensitizer and biomarker for several cancer tissues due to its presence in both intracellular as well as extracellular environment.

Acknowledgments and funding information We would like to thank Suhail Ansari and Rasmi Mishra for their critical reading of the manuscript and valuable suggestions. This work is, in part, supported by the European Molecular Biology Organization (EMBO) Installation Grant (Grant No. 2791) and TUBITAK (Grant No. 214S104).

\section{Compliance with ethical standards}

Conflict of interest The authors declare that they have no conflict of interest.

\section{References}

1. Bartel DP (2004) MicroRNAs: genomics, biogenesis, mechanism, and function. Cell 116:281-297

2. Lee RC, Feinbaum RL, Ambros V (1993) The C. elegans heterochronic gene lin- 4 encodes small RNAs with antisense complementarity to lin-14. Cell 75:843-854

3. Vella MC, Choi EY, Lin SY, Reinert K, Slack FJ (2004) The C. elegans microRNA let-7 binds to imperfect let-7 complementary sites from the lin-41 3'UTR. Genes Dev 18:132-137

4. Kaufman EJ, Miska EA (2010) The microRNAs of Caenorhabditis elegans. Semin Cell Dev Biol 21:728-737

5. Lagos-Quintana M, Rauhut R, Lendeckel W, Tuschl T (2001) Identification of novel genes coding for small expressed RNAs. Science 294:853-858

6. Pasquinelli AE, Reinhart BJ, Slack F, Martindale MQ, Kuroda MI, Maller B, Hayward DC, Ball EE, Degnan B, Muller P et al (2000) Conservation of the sequence and temporal expression of let-7 heterochronic regulatory RNA. Nature 408:86-89

7. Kozomara A, Griffiths-Jones S (2014) miRBase: annotating high confidence microRNAs using deep sequencing data. Nucleic Acids Res 42:D68-73

8. Friedman RC, Farh KK, Burge CB, Bartel DP (2009) Most mammalian mRNAs are conserved targets of microRNAs. Genome Res 19:92-105

9. Trang P, Weidhaas JB, Slack FJ (2008) MicroRNAs as potential cancer therapeutics. Oncogene 27(Suppl 2):S52-57 
10. Fasanaro P, Greco S, Ivan M, Capogrossi MC, Martelli F (2010) microRNA: emerging therapeutic targets in acute ischemic diseases. Pharmacol Ther 125:92-104

11. Hydbring P, Badalian-Very G (2013) Clinical applications of microRNAs. F1000Research 2:136

12. Li C, Feng Y, Coukos G, Zhang L (2009) Therapeutic microRNA strategies in human cancer. AAPS J 11:747-757

13. Hurteau GJ, Spivack SD, Brock GJ (2006) Potential mRNA degradation targets of hsa-miR-200c, identified using informatics and qRT-PCR. Cell Cycle 5:1951-1956

14. Humphries B, Yang C (2015) The microRNA-200 family: small molecules with novel roles in cancer development, progression and therapy. Oncotarget 6:6472-6498

15. Mutlu M, Saatci Ö, Raza U, Eyüpoglu E, Yurdusev E, Sahin Ö (2015) MIR200C (microRNA 200c). Atlas Genet Cytogenet Oncol Haematol 19:270-285

16. Burk U, Schubert J, Wellner U, Schmalhofer O, Vincan E, Spaderna S, Brabletz T (2008) A reciprocal repression between ZEB1 and members of the miR-200 family promotes EMT and invasion in cancer cells. EMBO Rep 9:582-589

17. Browne G, Sayan AE, Tulchinsky E (2010) ZEB proteins link cell motility with cell cycle control and cell survival in cancer. Cell Cycle 9:886-891

18. Sanchez-Tillo E, Lazaro A, Torrent R, Cuatrecasas M, Vaquero EC, Castells A, Engel P, Postigo A (2010) ZEB1 represses Ecadherin and induces an EMT by recruiting the SWI/SNF chromatin-remodeling protein BRG1. Oncogene 29:3490-3500

19. Mizuguchi Y, Specht S, Lunz JG 3rd, Isse K, Corbitt N, Takizawa $\mathrm{T}$, Demetris AJ (2012) Cooperation of p300 and PCAF in the control of microRNA 200c/141 transcription and epithelial characteristics. PLoS One 7, e32449. doi:10.1371/journal.pone. 0032449

20. Peng $\mathrm{C}$, Li N, Ng YK, Zhang J, Meier F, Theis FJ, Merkenschlager M, Chen W, Wurst W, Prakash N (2012) A unilateral negative feedback loop between miR-200 microRNAs and Sox2/E2F3 controls neural progenitor cell-cycle exit and differentiation. J Neurosci Off J Soc Neurosci 32:13292-13308

21. Pieraccioli M, Imbastari F, Antonov A, Melino G, Raschella G (2013) Activation of miR200 by c-Myb depends on ZEB1 expression and miR200 promoter methylation. Cell Cycle 12: 2309-2320

22. Knouf EC, Garg K, Arroyo JD, Correa Y, Sarkar D, Parkin RK, Wurz K, O'Briant KC, Godwin AK, Urban ND et al (2012) An integrative genomic approach identifies p73 and p63 as activators of miR-200 microRNA family transcription. Nucleic Acids Res 40:499-510

23. Wang G, Guo X, Hong W, Liu Q, Wei T, Lu C, Gao L, Ye D, Zhou Y, Chen J et al (2013) Critical regulation of miR-200/ZEB2 pathway in Oct4/Sox2-induced mesenchymal-to-epithelial transition and induced pluripotent stem cell generation. Proc Natl Acad Sci U S A 110:2858-2863

24. Vrba L, Jensen TJ, Garbe JC, Heimark RL, Cress AE, Dickinson S, Stampfer MR, Futscher BW (2010) Role for DNA methylation in the regulation of miR-200c and miR-141 expression in normal and cancer cells. PLoS One 5, e8697. doi:10.1371/journal.pone. 0008697

25. Wiklund ED, Bramsen JB, Hulf T, Dyrskjot L, Ramanathan R, Hansen TB, Villadsen SB, Gao S, Ostenfeld MS, Borre M et al (2011) Coordinated epigenetic repression of the miR-200 family and miR-205 in invasive bladder cancer. Int J Cancer J Int du Cancer 128:1327-1334

26. Tryndyak VP, Beland FA, Pogribny IP (2010) E-cadherin transcriptional down-regulation by epigenetic and microRNA-200 family alterations is related to mesenchymal and drug-resistant phenotypes in human breast cancer cells. Int J Cancer J Int du Cancer 126:2575-2583
27. Lamouille S, Xu J, Derynck R (2014) Molecular mechanisms of epithelial-mesenchymal transition. Nat Rev Mol Cell Biol 15: 178-196

28. De Craene B, Berx G (2013) Regulatory networks defining EMT during cancer initiation and progression. Nat Rev Cancer 13: 97-110

29. Peinado H, Olmeda D, Cano A (2007) Snail, Zeb and bHLH factors in tumour progression: an alliance against the epithelial phenotype? Nat Rev Cancer 7:415-428

30. Yang J, Mani SA, Donaher JL, Ramaswamy S, Itzykson RA, Come C, Savagner P, Gitelman I, Richardson A, Weinberg RA (2004) Twist, a master regulator of morphogenesis, plays an essential role in tumor metastasis. Cell 117:927-939

31. Park SM, Gaur AB, Lengyel E, Peter ME (2008) The miR-200 family determines the epithelial phenotype of cancer cells by targeting the E-cadherin repressors ZEB1 and ZEB2. Genes Dev 22:894-907

32. Li L, Li B, Chen D, Liu L, Huang C, Lu Z, Lun L, Wan X (2015) miR-139 and miR-200c regulate pancreatic cancer endothelial cell migration and angiogenesis. Oncol Rep 34:51-58

33. Wellner U, Schubert J, Burk UC, Schmalhofer O, Zhu F, Sonntag A, Waldvogel B, Vannier C, Darling D, zur Hausen A et al (2009) The EMT-activator ZEB1 promotes tumorigenicity by repressing stemness-inhibiting microRNAs. Nat Cell Biol 11:1487-1495

34. Korpal M, Lee ES, Hu G, Kang Y (2008) The miR-200 family inhibits epithelial-mesenchymal transition and cancer cell migration by direct targeting of E-cadherin transcriptional repressors ZEB1 and ZEB2. J Biol Chem 283:14910-14914

35. Brabletz S, Brabletz T (2010) The ZEB/miR-200 feedback loopa motor of cellular plasticity in development and cancer? EMBO Rep 11:670-677

36. Shimono Y, Zabala M, Cho RW, Lobo N, Dalerba P, Qian D, Diehn M, Liu H, Panula SP, Chiao E et al (2009) Downregulation of miRNA-200c links breast cancer stem cells with normal stem cells. Cell 138:592-603

37. Bar M, Wyman SK, Fritz BR, Qi J, Garg KS, Parkin RK, Kroh EM, Bendoraite A, Mitchell PS, Nelson AM et al (2008) MicroRNA discovery and profiling in human embryonic stem cells by deep sequencing of small RNA libraries. Stem Cells 26: 2496-2505

38. Chang CJ, Chao CH, Xia W, Yang JY, Xiong Y, Li CW, Yu WH, Rehman SK, Hsu JL, Lee HH et al (2011) p53 regulates epithelialmesenchymal transition and stem cell properties through modulating miRNAs. Nat Cell Biol 13:317-323

39. Kim T, Veronese A, Pichiorri F, Lee TJ, Jeon YJ, Volinia S, Pineau P, Marchio A, Palatini J, Suh SS et al (2011) p53 regulates epithelial-mesenchymal transition through microRNAs targeting ZEB1 and ZEB2. J Exp Med 208:875-883

40. Rajabi H, Alam M, Takahashi H, Kharbanda A, Guha M, Ahmad R, Kufe D (2014) MUC1-C oncoprotein activates the ZEB1/miR200c regulatory loop and epithelial-mesenchymal transition. Oncogene 33:1680-1689

41. Jurmeister S, Baumann M, Balwierz A, Keklikoglou I, Ward A, Uhlmann S, Zhang JD, Wiemann S, Sahin O (2012) MicroRNA$200 \mathrm{c}$ represses migration and invasion of breast cancer cells by targeting actin-regulatory proteins FHOD1 and PPM1F. Mol Cell Biol 32:633-651

42. Sigloch FC, Burk UC, Biniossek ML, Brabletz T, Schilling O (2015) miR-200c dampens cancer cell migration via regulation of protein kinase A subunits. Oncotarget 6:23874-23889

43. Li J, Tan Q, Yan M, Liu L, Lin H, Zhao F, Bao G, Kong H, Ge C, Zhang $\mathrm{F}$ et al (2014) miRNA-200c inhibits invasion and metastasis of human non-small cell lung cancer by directly targeting ubiquitin specific peptidase 25. Mol Cancer 13:166 
44. Howe EN, Cochrane DR, Richer JK (2011) Targets of miR-200c mediate suppression of cell motility and anoikis resistance. Breast Cancer Res: BCR 13:R45

45. Perdigao-Henriques R, Petrocca F, Altschuler G, Thomas MP, Le MT, Tan SM, Hide W, Lieberman J (2015) miR-200 promotes the mesenchymal to epithelial transition by suppressing multiple members of the Zeb2 and Snaill transcriptional repressor complexes. Oncogene. doi:10.1038/onc.2015.69

46. Liu M, Casimiro MC, Wang C, Shirley LA, Jiao X, Katiyar S, Ju X, Li Z, Yu Z, Zhou J et al (2009) p21CIP1 attenuates Ras- and cMyc-dependent breast tumor epithelial mesenchymal transition and cancer stem cell-like gene expression in vivo. Proc Natl Acad Sci U S A 106:19035-19039

47. Li XL, Hara T, Choi Y, Subramanian M, Francis P, Bilke S, Walker RL, Pineda M, Zhu Y, Yang Y et al (2014) A p21-ZEB1 complex inhibits epithelial-mesenchymal transition through the microRNA 183-96-182 cluster. Mol Cell Biol 34:533-550

48. Gregory PA, Bert AG, Paterson EL, Barry SC, Tsykin A, Farshid G, Vadas MA, Khew-Goodall Y, Goodall GJ (2008) The miR-200 family and miR-205 regulate epithelial to mesenchymal transition by targeting ZEB1 and SIP1. Nat Cell Biol 10:593-601

49. Hamano R, Miyata H, Yamasaki M, Kurokawa Y, Hara J, Moon JH, Nakajima K, Takiguchi S, Fujiwara Y, Mori M et al (2011) Overexpression of miR-200c induces chemoresistance in esophageal cancers mediated through activation of the Akt signaling pathway. Clin Cancer Res: Off J Am Assoc Cancer Res 17: 3029-3038

50. Madhavan D, Zucknick M, Wallwiener M, Cuk K, Modugno C, Scharpff M, Schott S, Heil J, Turchinovich A, Yang R et al (2012) Circulating miRNAs as surrogate markers for circulating tumor cells and prognostic markers in metastatic breast cancer. Clin Cancer Res: Off J Am Assoc Cancer Res 18:5972-5982

51. Gottesman MM (2002) Mechanisms of cancer drug resistance. Annu Rev Med 53:615-627

52. Liu S, Tetzlaff MT, Cui R, Xu X (2012) miR-200c inhibits melanoma progression and drug resistance through down-regulation of BMI-1. Am J Pathol 181:1823-1835

53. Park IK, Morrison SJ, Clarke MF (2004) Bmi1, stem cells, and senescence regulation. J Clin Invest 113:175-179

54. Cittelly DM, Dimitrova I, Howe EN, Cochrane DR, Jean A, Spoelstra NS, Post MD, Lu X, Broaddus RR, Spillman MA et al (2012) Restoration of miR-200c to ovarian cancer reduces tumor burden and increases sensitivity to paclitaxel. Mol Cancer Ther 11:2556-2565

55. Cochrane DR, Spoelstra NS, Howe EN, Nordeen SK, Richer JK (2009) MicroRNA-200c mitigates invasiveness and restores sensitivity to microtubule-targeting chemotherapeutic agents. Mol Cancer Ther 8:1055-1066

56. Prislei S, Martinelli E, Mariani M, Raspaglio G, Sieber S, Ferrandina G, Shahabi S, Scambia G, Ferlini C (2013) MiR$200 \mathrm{c}$ and HuR in ovarian cancer. BMC Cancer 13:72

57. Tanaka S, Hosokawa M, Ueda K, Iwakawa S (2015) Effects of decitabine on invasion and exosomal expression of miR-200c and miR-141 in oxaliplatin-resistant colorectal cancer cells. Biol Pharm Bull 38:1272-1279

58. Kopp F, Wagner E, Roidl A (2014) The proto-oncogene KRAS is targeted by miR-200c. Oncotarget 5:185-195

59. Sui H, Cai GX, Pan SF, Deng WL, Wang Y, Chen ZS, Cai SJ, Zhu HR, Li Q (2014) miR-200c attenuates P-gp mediated MDR and metastasis by targeting JNK2/c-Jun signaling pathway in colorectal cancer. Mol Cancer Ther. doi:10.1158/1535-7163.MCT-140167

60. Kopp F, Oak PS, Wagner E, Roidl A (2012) miR-200c sensitizes breast cancer cells to doxorubicin treatment by decreasing TrkB and Bmil expression. PLoS One 7:e50469
61. Segal RA (2003) Selectivity in neurotrophin signaling: theme and variations. Annu Rev Neurosci 26:299-330

62. Brodeur GM, Minturn JE, Ho R, Simpson AM, Iyer R, Varela CR, Light JE, Kolla V, Evans AE (2009) Trk receptor expression and inhibition in neuroblastomas. Clin Cancer Res: Off J Am Assoc Cancer Res 15:3244-3250

63. Ho R, Eggert A, Hishiki T, Minturn JE, Ikegaki N, Foster P, Camoratto AM, Evans AE, Brodeur GM (2002) Resistance to chemotherapy mediated by TrkB in neuroblastomas. Cancer Res 62:6462-6466

64. Lee J, Jiffar T, Kupferman ME (2012) A novel role for BDNFTrkB in the regulation of chemotherapy resistance in head and neck squamous cell carcinoma. PLoS One 7, e30246. doi:10. 1371/journal.pone.0030246

65. Manavalan TT, Teng Y, Appana SN, Datta S, Kalbfleisch TS, Li Y, Klinge CM (2011) Differential expression of microRNA expression in tamoxifen-sensitive MCF-7 versus tamoxifen-resistant LY2 human breast cancer cells. Cancer Lett 313:26-43

66. Manavalan TT, Teng Y, Litchfield LM, Muluhngwi P, Al-Rayyan N, Klinge CM (2013) Reduced expression of miR-200 family members contributes to antiestrogen resistance in LY2 human breast cancer cells. PLoS One 8, e62334. doi:10.1371/journal. pone. 0062334

67. Flaherty KT, Infante JR, Daud A, Gonzalez R, Kefford RF, Sosman J, Hamid O, Schuchter L, Cebon J, Ibrahim N et al (2012) Combined BRAF and MEK inhibition in melanoma with BRAF V600 mutations. N Engl J Med 367:1694-1703

68. Liu S, Tetzlaff MT, Wang T, Yang R, Xie L, Zhang G, Krepler C, Xiao M, Beqiri M, Xu W et al (2015) miR-200c/Bmil axis and epithelial-mesenchymal transition contribute to acquired resistance to BRAF inhibitor treatment. Pigment Cell Melanoma Res 28:431-441

69. Gao C, Peng FH, Peng LK (2014) MiR-200c sensitizes clear-cell renal cell carcinoma cells to sorafenib and imatinib by targeting heme oxygenase-1. Neoplasma. doi:10.4149/neo_2014_083

70. Lin J, Liu C, Gao F, Mitchel RE, Zhao L, Yang Y, Lei J, Cai J (2013) miR-200c enhances radiosensitivity of human breast cancer cells. J Cell Biochem 114:606-615

71. Sun Q, Liu T, Yuan Y, Guo Z, Xie G, Du S, Lin X, Xu Z, Liu M, Wang W et al (2015) MiR-200c inhibits autophagy and enhances radiosensitivity in breast cancer cells by targeting UBQLN1. Int J Cancer J Int du Cancer 136:1003-1012

72. Cui FB, Liu Q, Li RT, Shen J, Wu PY, Yu LX, Hu WJ, Wu FL, Jiang CP, Yue GF et al (2014) Enhancement of radiotherapy efficacy by miR-200c-loaded gelatinase-stimuli PEG-Pep-PCL nanoparticles in gastric cancer cells. Int J Nanomedicine 9:2345-2358

73. Singh A, Settleman J (2010) EMT, cancer stem cells and drug resistance: an emerging axis of evil in the war on cancer. Oncogene 29:4741-4751

74. Raza U, Zhang JD, Sahin O (2014) MicroRNAs: master regulators of drug resistance, stemness, and metastasis. J Mol Med (Berl) 92: 321-336

75. Ceppi P, Mudduluru G, Kumarswamy R, Rapa I, Scagliotti GV, Papotti M, Allgayer H (2010) Loss of miR-200c expression induces an aggressive, invasive, and chemoresistant phenotype in non-small cell lung cancer. Mol Cancer Res: MCR 8:1207-1216

76. Puhr M, Hoefer J, Schafer G, Erb HH, Oh SJ, Klocker H, Heidegger I, Neuwirt H, Culig Z (2012) Epithelial-tomesenchymal transition leads to docetaxel resistance in prostate cancer and is mediated by reduced expression of miR-200c and miR-205. Am J Pathol 181:2188-2201

77. Li Y, VandenBoom TG 2nd, Kong D, Wang Z, Ali S, Philip PA, Sarkar FH (2009) Up-regulation of miR-200 and let-7 by natural agents leads to the reversal of epithelial-to-mesenchymal transition in gemcitabine-resistant pancreatic cancer cells. Cancer Res 69: 6704-6712 
78. Bao B, Wang Z, Ali S, Ahmad A, Azmi AS, Sarkar SH, Banerjee S, Kong D, Li Y, Thakur S et al (2012) Metformin inhibits cell proliferation, migration and invasion by attenuating CSC function mediated by deregulating miRNAs in pancreatic cancer cells. Cancer Prev Res 5:355-364

79. Ma C, Huang T, Ding YC, Yu W, Wang Q, Meng B, Luo SX (2015) microRNA-200c overexpression inhibits chemoresistance, invasion and colony formation of human pancreatic cancer stem cells. Int J Clin Exp Pathol 8:6533-6539

80. Brozovic A, Duran GE, Wang YC, Francisco EB, Sikic BI (2015) The miR-200 family differentially regulates sensitivity to paclitaxel and carboplatin in human ovarian carcinoma OVCAR-3 and MES-OV cells. Mol Oncol 9:1678-1693

81. Siebzehnrubl FA, Silver DJ, Tugertimur B, Deleyrolle LP, Siebzehnrubl D, Sarkisian MR, Devers KG, Yachnis AT, Kupper MD, Neal D et al (2013) The ZEB1 pathway links glioblastoma initiation, invasion and chemoresistance. EMBO Mol Med 5:1196-1212

82. Fischer KR, Durrans A, Lee S, Sheng J, Li F, Wong ST, Choi H, El Rayes T, Ryu S, Troeger J et al (2015) Epithelial-to-mesenchymal transition is not required for lung metastasis but contributes to chemoresistance. Nature 527:472-476

83. Adam L, Zhong M, Choi W, Qi W, Nicoloso M, Arora A, Calin G, Wang H, Siefker-Radtke A, McConkey D et al (2009) miR-200 expression regulates epithelial-to-mesenchymal transition in bladder cancer cells and reverses resistance to epidermal growth factor receptor therapy. Clin Cancer Res: Off J Am Assoc Cancer Res 15: 5060-5072

84. Shien K, Toyooka S, Yamamoto H, Soh J, Jida M, Thu KL, Hashida S, Maki Y, Ichihara E, Asano H et al (2013) Acquired resistance to EGFR inhibitors is associated with a manifestation of stem cell-like properties in cancer cells. Cancer Res 73:30513061

85. Cufi S, Bonavia R, Vazquez-Martin A, Oliveras-Ferraros C, Corominas-Faja B, Cuyas E, Martin-Castillo B, BarrajonCatalan E, Visa J, Segura-Carretero A et al (2013) Silibinin suppresses EMT-driven erlotinib resistance by reversing the high miR-21/low miR-200c signature in vivo. Sci Rep 3:2459

86. Bryant JL, Britson J, Balko JM, Willian M, Timmons R, Frolov A, Black EP (2012) A microRNA gene expression signature predicts response to erlotinib in epithelial cancer cell lines and targets EMT. Br J Cancer 106:148-156

87. Izumchenko EG, Chang X, Michailidi C, Kagohara LT, Ravi R, Paz K, Brait M, Hoque MO, Ling S, Bedi A et al (2014) The TGFbeta-miR200-Mig6 pathway orchestrates the EMTassociated kinase switch that induces resistance to EGFR inhibitors. Cancer Res. doi:10.1158/0008-5472.CAN-14-0110

88. Bai WD, Ye XM, Zhang MY, Zhu HY, Xi WJ, Huang X, Zhao J, Gu B, Zheng GX, Yang AG et al (2014) MiR-200c suppresses TGF-beta signaling and counteracts trastuzumab resistance and metastasis by targeting ZNF217 and ZEB1 in breast cancer. Int J Cancer J Int du Cancer. doi:10.1002/ijc.28782

89. Shi SJ, Wang LJ, Yu B, Li YH, Jin Y, Bai XZ (2015) LncRNAATB promotes trastuzumab resistance and invasion-metastasis cascade in breast cancer. Oncotarget 6:11652-11663

90. Rebustini IT, Hayashi T, Reynolds AD, Dillard ML, Carpenter EM, Hoffman MP (2012) miR-200c regulates FGFR-dependent epithelial proliferation via Vldlr during submandibular gland branching morphogenesis. Development 139:191-202

91. Cao H, Jheon A, Li X, Sun Z, Wang J, Florez S, Zhang Z, McManus MT, Klein OD, Amendt BA (2013) The Pitx2:miR200c/141:noggin pathway regulates Bmp signaling and ameloblast differentiation. Development 140:3348-3359

92. Li H, Xu L, Li C, Zhao L, Ma Y, Zheng H, Li Z, Zhang Y, Wang R, Liu Y et al (2014) Ubiquitin ligase Cbl-b represses IGF-I-induced epithelial mesenchymal transition via ZEB2 and microRNA-200c regulation in gastric cancer cells. Mol Cancer 13:136

93. Song C, Liu LZ, Pei XQ, Liu X, Yang L, Ye F, Xie X, Chen J, Tang H, Xie X (2015) miR-200c inhibits breast cancer proliferation by targeting KRAS. Oncotarget

94. Park JT, Kato M, Yuan H, Castro N, Lanting L, Wang M, Natarajan R (2013) FOG2 protein down-regulation by transforming growth factor-betal-induced microRNA-200b/c leads to Akt kinase activation and glomerular mesangial hypertrophy related to diabetic nephropathy. J Biol Chem 288:2246922480

95. Howe EN, Cochrane DR, Cittelly DM, Richer JK (2012) miR200c targets a NF-kappaB up-regulated TrkB/NTF3 autocrine signaling loop to enhance anoikis sensitivity in triple negative breast cancer. PLoS One 7:e49987

96. Schickel R, Park SM, Murmann AE, Peter ME (2010) miR-200c regulates induction of apoptosis through CD95 by targeting FAP1. Mol Cell 38:908-915

97. Ren Y, Han X, Yu K, Sun S, Zhen L, Li Z, Wang S (2014) microRNA-200c downregulates XIAP expression to suppress proliferation and promote apoptosis of triple-negative breast cancer cells. Mol Med Rep 10:315-321

98. Huang HN, Chen SY, Hwang SM, Yu CC, Su MW, Mai W, Wang HW, Cheng WC, Schuyler SC, Ma N et al (2014) miR-200c and GATA binding protein 4 regulate human embryonic stem cell renewal and differentiation. Stem Cell Res 12:338-353

99. Lu YX, Yuan L, Xue XL, Zhou M, Liu Y, Zhang C, Li JP, Zheng L, Hong M, Li XN (2014) Regulation of colorectal carcinoma stemness, growth, and metastasis by an miR-200c-Sox2-negative feedback loop mechanism. Clin Cancer Res: Off J Am Assoc Cancer Res 20:2631-2642

100. Klein D, Misawa R, Bravo-Egana V, Vargas N, Rosero S, Piroso J, Ichii H, Umland O, Zhijie J, Tsinoremas N et al (2013) MicroRNA expression in alpha and beta cells of human pancreatic islets. PLoS One 8, e55064. doi:10.1371/journal.pone.0055064

101. Luo X, Dong Z, Chen Y, Yang L, Lai D (2013) Enrichment of ovarian cancer stem-like cells is associated with epithelial to mesenchymal transition through an miRNA-activated AKT pathway. Cell Prolif 46:436-446

102. Vallejo DM, Caparros E, Dominguez M (2011) Targeting Notch signalling by the conserved miR-8/200 microRNA family in development and cancer cells. EMBO J 30:756-769

103. Bao B, Wang Z, Ali S, Kong D, Li Y, Ahmad A, Banerjee S, Azmi AS, Miele L, Sarkar FH (2011) Notch-1 induces epithelialmesenchymal transition consistent with cancer stem cell phenotype in pancreatic cancer cells. Cancer Lett 307:26-36

104. Mezquita B, Mezquita J, Barrot C, Carvajal S, Pau M, Mezquita P, Mezquita C (2014) A truncated-Flt1 isoform of breast cancer cells is upregulated by Notch and downregulated by retinoic acid. J Cell Biochem 115:52-61

105. Mezquita B, Mezquita P, Pau M, Mezquita J, Mezquita C (2014) Unlocking doors without keys: activation of Src by truncated Cterminal intracellular receptor tyrosine kinases lacking tyrosine kinase activity. Cells 3:92-111

106. Wendlandt EB, Graff JW, Gioannini TL, McCaffrey AP, Wilson ME (2012) The role of microRNAs miR-200b and miR-200c in TLR4 signaling and NF-kappaB activation. Innate Immun 18: 846-855

107. Rokavec M, Wu W, Luo JL (2012) IL6-mediated suppression of miR-200c directs constitutive activation of inflammatory signaling circuit driving transformation and tumorigenesis. Mol Cell 45: 777-789

108. Chuang TD, Khorram O (2014) miR-200c regulates IL8 expression by targeting IKBKB: a potential mediator of inflammation in leiomyoma pathogenesis. PLoS One 9:e95370 
109. Lobert S, Graichen ME, Morris K (2013) Coordinated regulation of beta-tubulin isotypes and epithelial-to-mesenchymal transition protein ZEB1 in breast cancer cells. Biochemistry 52:5482-5490

110. Hur K, Toiyama Y, Takahashi M, Balaguer F, Nagasaka T, Koike J, Hemmi H, Koi M, Boland CR, Goel A (2013) MicroRNA-200c modulates epithelial-to-mesenchymal transition (EMT) in human colorectal cancer metastasis. Gut 62:1315-1326

111. Oishi N, Kumar MR, Roessler S, Ji J, Forgues M, Budhu A, Zhao X, Andersen JB, Ye QH, Jia HL et al (2012) Transcriptomic profiling reveals hepatic stem-like gene signatures and interplay of miR-200c and epithelial-mesenchymal transition in intrahepatic cholangiocarcinoma. Hepatology 56:1792-1803

112. Karakatsanis A, Papaconstantinou I, Gazouli M, Lyberopoulou A, Polymeneas G, Voros D (2013) Expression of microRNAs, miR21, miR-31, miR-122, miR-145, miR-146a, miR-200c, miR-221, miR-222, and miR-223 in patients with hepatocellular carcinoma or intrahepatic cholangiocarcinoma and its prognostic significance. Mol Carcinog 52:297-303

113. Lahat G, Lubezky N, Loewenstein S, Nizri E, Gan S, PasmanikChor M, Hayman L, Barazowsky E, Ben-Haim M, Klausner JM (2014) Epithelial-to-Mesenchymal Transition (EMT) in Intraductal Papillary Mucinous Neoplasm (IPMN) is associated with high tumor grade and adverse outcomes. Ann Surg Oncol. doi:10.1245/s10434-014-3946-5

114. Kim MK, Jung SB, Kim JS, Roh MS, Lee JH, Lee EH, Lee HW (2014) Expression of microRNA miR-126 and miR-200c is associated with prognosis in patients with non-small cell lung cancer. Virchows Archiv: Int J Pathol. doi:10.1007/s00428-014-1640-4

115. Tejero R, Navarro A, Campayo M, Vinolas N, Marrades RM, Cordeiro A, Ruiz-Martinez M, Santasusagna S, Molins L, Ramirez J et al (2014) miR-141 and miR-200c as markers of overall survival in early stage non-small cell lung cancer adenocarcinoma. PLoS One 9:e101899

116. Pacurari M, Addison JB, Bondalapati N, Wan YW, Luo D, Qian Y, Castranova V, Ivanov AV, Guo NL (2013) The microRNA-200 family targets multiple non-small cell lung cancer prognostic markers in H1299 cells and BEAS-2B cells. Int J Oncol 43: $548-560$

117. Zhang HH, Zhang ZY, Che CL, Mei YF, Shi YZ (2013) Array analysis for potential biomarker of gemcitabine identification in non-small cell lung cancer cell lines. Int J Clin Exp Pathol 6: $1734-1746$

118. Leskela S, Leandro-Garcia LJ, Mendiola M, Barriuso J, IngladaPerez L, Munoz I, Martinez-Delgado B, Redondo A, de Santiago $\mathrm{J}$, Robledo $\mathrm{M}$ et al (2011) The miR-200 family controls betatubulin III expression and is associated with paclitaxel-based treatment response and progression-free survival in ovarian cancer patients. Endocrine-Related Cancer 18:85-95

119. Marchini S, Cavalieri D, Fruscio R, Calura E, Garavaglia D, Nerini IF, Mangioni C, Cattoretti G, Clivio L, Beltrame L et al (2011) Association between miR-200c and the survival of patients with stage I epithelial ovarian cancer: a retrospective study of two independent tumour tissue collections. Lancet Oncol 12:273-285

120. White NM, Bao TT, Grigull J, Youssef YM, Girgis A, Diamandis M, Fatoohi E, Metias M, Honey RJ, Stewart R et al (2011) miRNA profiling for clear cell renal cell carcinoma: biomarker discovery and identification of potential controls and consequences of miRNA dysregulation. J Urol 186:1077-1083

121. Fridman E, Dotan Z, Barshack I, David MB, Dov A, Tabak S, Zion O, Benjamin S, Benjamin H, Kuker H et al (2010) Accurate molecular classification of renal tumors using microRNA expression. J Mol Diagn: JMD 12:687-696

122. Wotschofsky Z, Busch J, Jung M, Kempkensteffen C, Weikert S, Schaser KD, Melcher I, Kilic E, Miller K, Kristiansen G et al (2013) Diagnostic and prognostic potential of differentially expressed miRNAs between metastatic and non-metastatic renal cell carcinoma at the time of nephrectomy. Clin Chim Acta 416:5-10

123. Mahdavinezhad A, Mousavi-Bahar SH, Poorolajal J, Yadegarazari R, Jafari M, Shabab N, Saidijam M (2015) Evaluation of miR-141, miR-200c, miR-30b expression and clinicopathological features of bladder cancer. Int J Mol Cell Med 4:32-39

124. Berber U, Yilmaz I, Narli G, Haholu A, Kucukodaci Z, Demirel D (2014) miR-205 and miR-200c: predictive micro RNAs for lymph node metastasis in triple negative breast cancer. J Breast Cancer 17:143-148

125. Toiyama Y, Hur K, Tanaka K, Inoue Y, Kusunoki M, Boland CR, Goel A (2014) Serum miR-200c is a novel prognostic and metastasis-predictive biomarker in patients with colorectal cancer. Ann Surg 259:735-743

126. Paraskevi A, Theodoropoulos G, Papaconstantinou I, Mantzaris G, Nikiteas N, Gazouli M (2012) Circulating MicroRNA in inflammatory bowel disease. JCrohn's Colitis 6:900-904

127. Valladares-Ayerbes M, Reboredo M, Medina-Villaamil V, Iglesias-Diaz P, Lorenzo-Patino MJ, Haz M, Santamarina I, Blanco M, Fernandez-Tajes J, Quindos M et al (2012) Circulating miR-200c as a diagnostic and prognostic biomarker for gastric cancer. J Transl Med 10:186

128. Yun KW, Lee JY, Yun SW, Lim IS, Choi ES (2014) Elevated serum level of microRNA (miRNA)-200c and miRNA-371$5 \mathrm{p}$ in children with Kawasaki disease. Pediatr Cardiol 35: $745-752$

129. Liu XG, Zhu WY, Huang YY, Ma LN, Zhou SQ, Wang YK, Zeng F, Zhou JH, Zhang YK (2012) High expression of serum miR-21 and tumor miR-200c associated with poor prognosis in patients with lung cancer. Med Oncol 29:618-626

130. Taylor DD, Gercel-Taylor C (2008) MicroRNA signatures of tumor-derived exosomes as diagnostic biomarkers of ovarian cancer. Gynecol Oncol 110:13-21

131. Kan CW, Hahn MA, Gard GB, Maidens J, Huh JY, Marsh DJ, Howell VM (2012) Elevated levels of circulating microRNA-200 family members correlate with serous epithelial ovarian cancer. BMC Cancer 12:627

132. Cheng HH, Mitchell PS, Kroh EM, Dowell AE, Chery L, Siddiqui J, Nelson PS, Vessella RL, Knudsen BS, Chinnaiyan AM et al (2013) Circulating microRNA profiling identifies a subset of metastatic prostate cancer patients with evidence of cancer-associated hypoxia. PLoS One 8, e69239. doi:10.1371/journal.pone.0069239

133. Lv LL, Cao Y, Liu D, Xu M, Liu H, Tang RN, Ma KL, Liu BC (2013) Isolation and quantification of microRNAs from urinary exosomes/microvesicles for biomarker discovery. Int J Biol Sci 9: 1021-1031

134. Zuberi M, Mir R, Das J, Ahmad I, Javid J, Yadav P, Masroor M, Ahmad S, Ray PC, Saxena A (2015) Expression of serum miR200a, miR-200b, and miR-200c as candidate biomarkers in epithelial ovarian cancer and their association with clinicopathological features. Clin Transl Oncol 17:779-787

135. Hong L, Han Y, Zhang H, Fan D (2015) Prognostic markers in esophageal cancer: from basic research to clinical use. Expert Rev Gastroenterol Hepatol 9:887-889

136. Pantel K, Alix-Panabieres C (2010) Circulating tumour cells in cancer patients: challenges and perspectives. Trends Mol Med 16:398-406

137. Perez-Hernandez J, Forner MJ, Pinto C, Chaves FJ, Cortes R, Redon J (2015) Increased urinary exosomal micrornas in patients with systemic lupus erythematosus. PLoS One 10, e0138618. doi: 10.1371/journal.pone.0138618

138. Yuan JH, Yang F, Wang F, Ma JZ, Guo YJ, Tao QF, Liu F, Pan W, Wang TT, Zhou CC et al (2014) A long noncoding RNA activated 
by TGF-beta promotes the invasion-metastasis cascade in hepatocellular carcinoma. Cancer Cell 25:666-681

139. Xiao X, Yu S, Li S, Wu J, Ma R, Cao H, Zhu Y, Feng J (2014) Exosomes: decreased sensitivity of lung cancer A549 cells to cisplatin. PLoS One 9, e89534. doi:10.1371/journal.pone. 0089534

140. Chen Y, Gao DY, Huang L (2015) In vivo delivery of miRNAs for cancer therapy: challenges and strategies. Adv Drug Deliv Rev 81: 128-141

141. Esposito CL, Cerchia L, Catuogno S, De Vita G, Dassie JP, Santamaria G, Swiderski P, Condorelli G, Giangrande PH, de
Franciscis V (2014) Multifunctional aptamer-miRNA conjugates for targeted cancer therapy. Mol Ther: J Am Soc Gene Ther 22: $1151-1163$

142. Cortez MA, Valdecanas D, Zhang X, Zhan Y, Bhardwaj V, Calin GA, Komaki R, Giri DK, Quini CC, Wolfe T et al (2014) Therapeutic delivery of miR-200c enhances radiosensitivity in lung cancer. Mol Ther: J Am Soc Gene Ther. doi:10.1038/mt. 2014.79

143. Li XJ, Ren ZJ, Tang JH (2014) MicroRNA-34a: a potential therapeutic target in human cancer. Cell Death Dis 5, e1327. doi:10. 1038/cddis. 2014.270 